\title{
ProduCCIÓN Y DISTRIBUCIÓN ALFARERA COLONIAL TEMPRANA EN LOS ANDES CENTRALES: MODELOS Y CASOS ${ }^{1}$
}

\author{
Gabriel Ramón ${ }^{a}$
}

\begin{abstract}
Resumen
¿Cómo el régimen colonial temprano afectó el oficio de alfarero en los Andes? ¿Cómo la evidencia documental y material sobre alfarería nos permite comprender mejor ese periodo? Este articulo propone una metodología para responder ambas interrogantes. Con tal objetivo, se sugiere la necesidad de emplear modelos analíticos explícitos sobre alfareros cuando se estudia evidencia cerámica. En este contexto, se proponen algunos modelos alfareros para el periodo colonial temprano y se discuten tres casos específicos que muestran la diversidad de estrategias empleadas por los alfareros en ese periodo.
\end{abstract}

Palabras clave: producción alfarera colonial, cerámica colonial, arqueología colonial andina, estilos técnicos, olleros

\section{Abstract \\ PRODUCTION AND DISTRIBUTION OF EARLY COLONIAL POTTERY IN THE CENTRAL ANDES: MODELS AND CASES}

How did the early colonial regime impact the potter's craft in the Andes? How can documentary and material evidence of pottery production allow us to better understand that period? This article proposes a methodology to answer both questions. It suggests that it is necessary to use explicit analytic models about potters when dealing with ceramic evidence. In this context, several models about potters are proposed for the early colonial period, and three specific cases showing the diversity of strategies employed by artisans of that period are discussed.

Keywords: colonial pottery production, Andean colonial archaeology, technical styles, olleros

${ }^{a}$ Departamento de Humanidades, Pontificia Universidad Católica del Perú

Correo electrónico: glramon@pucp.edu.pe 
Pue[s] óyeme atentamente. Quando el ollero está haziendo jarros, y ollas, unos para la mesa de los señores, y otros para la cozina, podrá la olla quejarse al ollero (si tuviera entendimiento) y dezirle: Para qué me hiziste olla para la cozina, y no me hiziste jarro para la mesa de los señores? No por cierto. Porque?...

F. Avendaño, Sermones de los misterios de nuestra santa Fe...., 1648, Lima, 71v

\section{Introducción}

Buena parte de la arqueología precolonial andina depende de la evidencia alfarera para establecer cronologías relativas o definir unidades colectivas (v.g. estilos). Entre los ejercicios más sofisticados en este campo destaca el estudio de Menzel (1977), una síntesis articulada que usa como eje narrativo las cronologías alfareras, desarrolladas con su equipo de investigación. Sin embargo, escudrińando ese trabajo podemos percibir que la explicación no solo reposa en la cronología sino también en el modelo alfarero empleado. Este modelo puede definirse como la manera en que cada autor asume que se concatenaron socialmente los diversos pasos de la cadena operativa alfarera. Entre otras, incluye las siguientes interrogantes: ¿Dónde estaban las áreas de producción?, ¿cuál era su relación con las canteras?, ¿cómo se realizaba la distribución de las vasijas?, ¿se desplazaban los alfareros para producirlas y/o distribuirlas? En las últimas décadas estas preguntas han ido adquiriendo mayor peso en la literatura arqueológica andina, ya que resulta evidente que nuestra descripción de las sociedades precoloniales irá variando según las respuestas que propongamos ${ }^{2}$.

En arqueología colonial andina convendría asumir un programa semejante al indicado, partiendo por considerar la cronología y los modelos alfareros. Si bien ya contamos con un actualizado relato del periodo colonial temprano basado en evidencia documental, se ha explorado poco su contraparte material, especialmente los objetos portátiles cotidianos. La cerámica es ideal para articular ambos universos. En esa perspectiva, considerando las preguntas indicadas sobre la cadena operativa, exploraremos la transformación del oficio alfarero entre fines del Horizonte Tardío hasta la consolidación de las reducciones indígenas en el virreinato peruano ${ }^{3}$.

En arqueología los modelos alfareros más difundidos para lidiar con las formas de producción y/o distribución suelen apoyarse en aproximaciones deductivas, v.g. serie de posibilidades lógicas postuladas por un autor. Sin embargo, la riqueza de datos documentales y materiales para regiones como los Andes peruanos, invita a un enfoque distinto, que brinda un sabor más concreto a los modelos, localizándolos. Seguidamente, tras presentar las coordenadas generales, discutiremos una cronología y tipología básicas de alfareros coloniales tempranos. Esto servirá de contexto a tres casos releídos con los elementos propuestos.

\section{Coordenadas}

La historia precolonial andina es elaborada empleando tres bases de datos referenciales: evidencia arqueológica (principalmente objetos decorados), la matriz analógica (documentación del primer siglo colonial, con indicios sobre modos de vida previos) y el presente etnográfico (información recogida por etnógrafos desde fines del diecinueve) (Ramón 2008a: 1-37). Los arqueólogos reconocen unánimemente la primera base de datos, y casi todos la segunda. Sin embargo, muchos siguen consternados por el espectro de la analogía etnográfica, pese a emplearla cotidianamente en sus explicaciones del material precolonial (Wylie 2002: 136-153). Por coincidencia cronológica, en la arqueología colonial temprana la matriz analógica resulta también evidencia directa, lo cual permite replantear las relaciones entre las tres bases de datos mencionadas. Insistiré aquí en la importancia de las dos últimas para entender lo que hallamos en el registro arqueológico sobre alfareros inmediatamente antes y después de 1532. 


\begin{tabular}{|c|c|c|c|}
\hline & \multicolumn{3}{|c|}{ ANDES } \\
\hline Renfrew (1974) & Salomon (1985) & Sabogal (1987) & Sillar (2000) \\
\hline 1. Acceso directo & \multirow{3}{*}{$\begin{array}{l}\text { 1. Descentralizado }(1)^{1} \\
\text { 2. Centralizado }(1,2)\end{array}$} & $\begin{array}{l}\text { 1. Olleros trashumantes } \\
\text { (costa) }\end{array}$ & $\begin{array}{l}\text { 0. Producción para uso } \\
\text { propio }\end{array}$ \\
\hline $\begin{array}{l}\text { 2. Reciprocidad de } \\
\text { base doméstica }\end{array}$ & & $\begin{array}{l}\text { 2. Olleros trashumantes } \\
\text { (sierra-costa) }\end{array}$ & $\begin{array}{c}\text { 1. Intercambio en la } \\
\text { comunidad }\end{array}$ \\
\hline $\begin{array}{l}\text { 3. Reciprocidad de } \\
\text { frontera }\end{array}$ & & $\begin{array}{l}\text { 3. Alfarero-buhonero } \\
\text { (vendedor itinerante) }\end{array}$ & $\begin{array}{c}\text { 2. Consumidores } \\
\text { visitando la casa del } \\
\text { alfarero } \\
\end{array}$ \\
\hline $\begin{array}{l}\text { 4. Intercambio en } \\
\text { cualquier punto }\end{array}$ & \multirow{3}{*}{$\begin{array}{l}\text { Relación diádica } \\
\text { 3. Descentralizada }(2,3) \\
\text { 4. Centralizada }(4,8)\end{array}$} & $\begin{array}{c}\text { 4. La esposa o hija del } \\
\text { alfarero } \\
\text { (vendedora itinerante) }\end{array}$ & 3. Mercado semanales \\
\hline $\begin{array}{l}\text { 5. Lugar central: } \\
\text { distribución }\end{array}$ & & $\begin{array}{c}\text { 5. Alfareros no } \\
\text { convencionales } \\
\text { (artistas de Chulucanas) }\end{array}$ & 4. Ferias anuales \\
\hline $\begin{array}{l}\text { 6. Lugar central : } \\
\text { mercado }\end{array}$ & & $\begin{array}{c}\text { 6. Fabricante de huacos } \\
\text { artificiales }\end{array}$ & $\begin{array}{c}\text { 5. Alfareros itinerantes } \\
{[1,2,8]^{2}}\end{array}$ \\
\hline $\begin{array}{l}\text { 7. Intercambio libre } \\
\text { (intermediario) }\end{array}$ & \multirow{3}{*}{$\begin{array}{c}\text { Intercambio de } \\
\text { alianza múltiple } \\
\text { 5. Descentralizado }(2,7) \\
\text { 6. Centralizado }(8,9)\end{array}$} & $\begin{array}{l}\text { 7. Producción cerámica } \\
\text { urbana } \\
\text { (modelos importados) }\end{array}$ & $\begin{array}{c}\text { 6. Vendedores } \\
\text { itinerantes (alfareros o } \\
\text { intermediarios) }[3,4]\end{array}$ \\
\hline $\begin{array}{l}\text { 8. Intercambio con } \\
\text { emisarios }\end{array}$ & & \multirow{3}{*}{$\begin{array}{l}\text { 8. Ollero del pueblo } \\
\text { (usualmente foráneo, } \\
\text { venta realizada por } \\
\text { parientes femeninos) }\end{array}$} & $\begin{array}{l}\text { 7. Al por mayor } \\
\text { (intermediarios) }\end{array}$ \\
\hline 9. Enclave colonial & & & \multirow[b]{2}{*}{ 8. Mercado diario } \\
\hline $\begin{array}{l}\text { 10. Puerto de } \\
\text { intercambio }\end{array}$ & $\begin{array}{c}\text { Trueque abierto } \\
\text { 7. Descentralizado } \\
(2,3,4) \\
\text { 8. Centralizado }(6,10)\end{array}$ & & \\
\hline
\end{tabular}

Tabla 1. Tipologias de intercambio alfarero (Sabogal 1987; Sillar 2000).

Los dos ejes clave de la arqueología andina (cronología relativa y el concepto de identidad colectiva) fueron trazados empleando los estilos decorativos de las vasijas. Recientemente, métodos alternativos a la seriación estilística por parecido (sensu Rowe 1962), están permitiendo trazar vínculos entre unidades colectivas precoloniales (comunidades, sociedades, etc.) difíciles de rastrear usando exclusivamente estilos decorativos. La atención a la cerámica doméstica está permitiendo una aproximación entre métodos y agendas relativamente recientes, tales como el análisis por activación de neutrones para vincular vasijas de cerámica y sus potenciales canteras, y la historia subalterna para visibilizar a los grupos ignorados en la narrativa histórica tradicional (Ramón y Bell 2013: 595-596, 609, passim). Entendámonos, el valioso armazón basado en estilos decorativos seguirá siendo imprescindible, pero es solo la ventana hacia una historia más amplia, elaborada mediante la incorporación de elementos como el estilo técnico ${ }^{4}$. Establecer nexos usando este tipo de evidencia presente en las vasijas, permitirá incorporar más objetos en la explicación (vasijas llanas, domésticas), re-leer los patrones de distribución de las vasijas decoradas y revelar otras historias vinculadas a grupos sistemáticamente soslayados en arqueología. La coyuntura actual tiene dos rasgos destacables. Primero, los alfareros confirman su importancia como productores de la evidencia arqueológica y, sobre todo, como sujetos históricos en sí. Segundo, la arqueología colonial está en lugar privilegiado para pensar nuestros modelos alfareros, incluso precoloniales.

Cuando los arqueólogos van de la teoría a los fragmentos surgen turbulencias al momento de tener que indicar el modelo alfarero que están asumiendo para articular sus explicaciones: es el espectro de la analogía etnográfica ${ }^{5}$. En la arqueología precolonial nuestra interpretación de la evidencia cerámica depende del modelo alfarero adoptado, generado desde la etnografía. En la arqueología colonial hay dos ventajas analíticas. Primero, contamos con evidencia documental sobre alfarería. Segundo, los modelos etnográficos están cronológicamente más próximos al material excavado. En suma, una relectura en clave etnográfica brinda mayor visibilidad a la evidencia documental sobre producción y distribución alfarera ${ }^{6}$. 


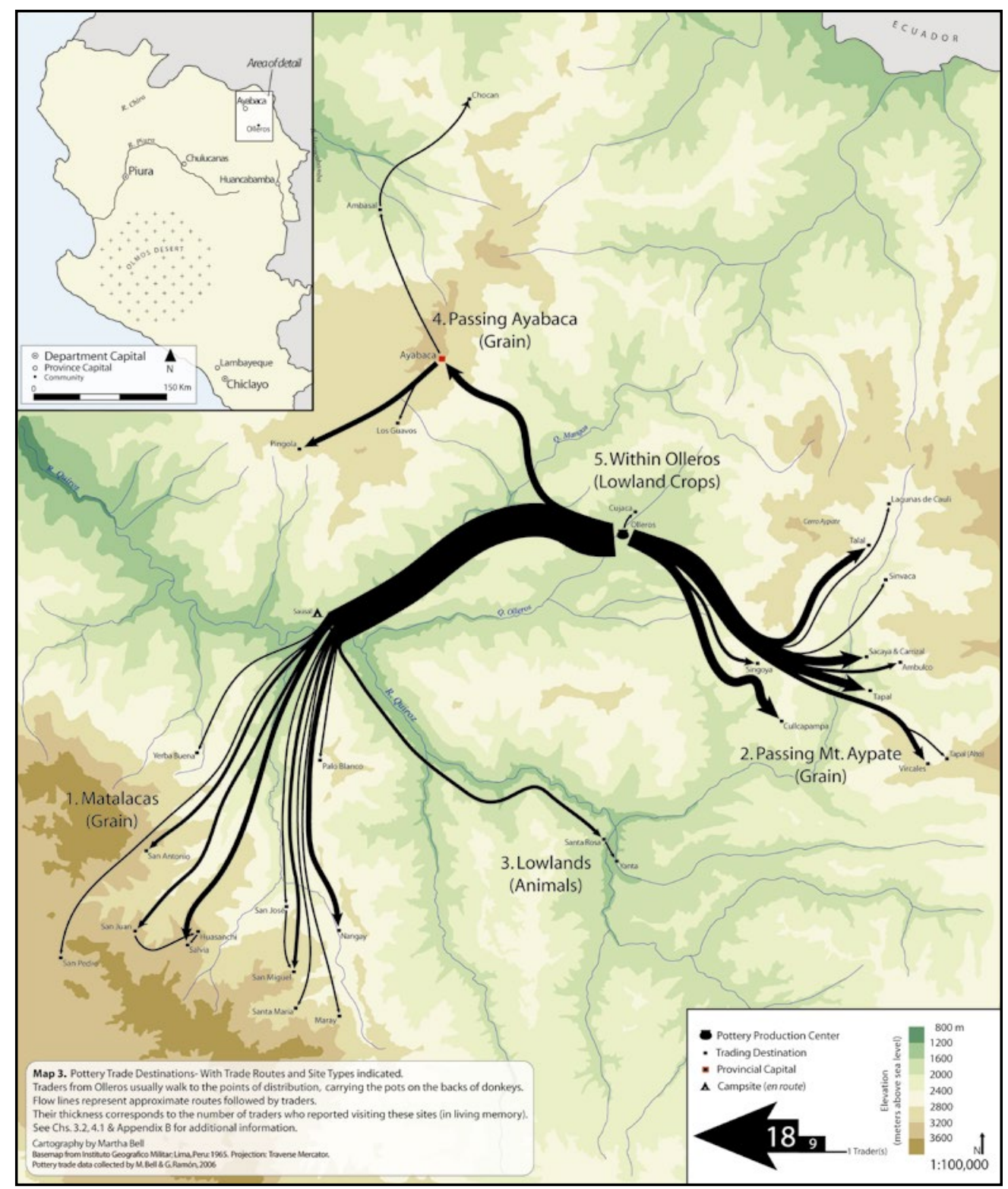

Figura 1. Red de distribución alfarera en San Bartolomé de los Olleros, Ayabaca, Piura (Bell 2007). El grosor de la línea indica el monto de alfareros que realizan el viaje.

\section{Localizando alfareros (1549-1632)}

Para organizar la información sobre formas de intercambio en los Andes, Salomon (1985) esbozó una tipología funcional de ocho posibilidades contrastando casos empíricos (etnográficos o históricos) con el esquema deductivo de Renfrew (1974). Aunque ambos lidiaron con la distribución de objetos en general, posteriormente los etnógrafos han planteado tipologías articulando producción y distribución alfareras (Sabogal 1987, Sillar 2000) (Tabla 1). Un ejemplo más reciente, considerando los productos intercambiados por las vasijas (granos, cultivos de tierras bajas, animales), tipos de vasijas y volumen de circulación fue propuesto para San Bartolomé de los Olleros, Piura 


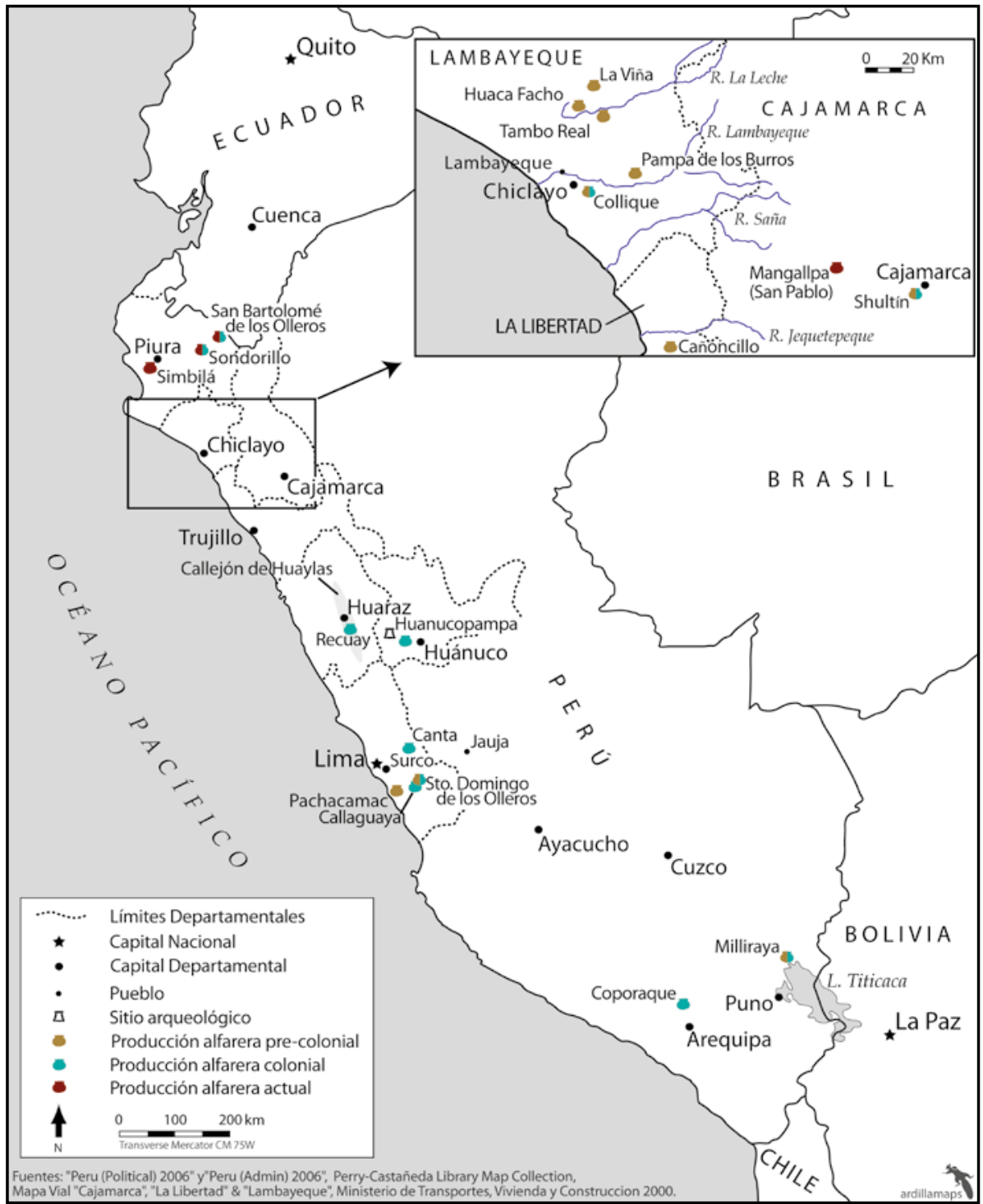

Figura 2. Algunos lugares mencionados en el texto.

(Bell 2007: 98) (Fig. 1)7 . Frente a esta detallada evidencia etnográfica, la documentación colonial temprana disponible es mínima. Los arqueólogos han empleado esta información retrospectivamente para entender el Horizonte Tardío (Hayashida 1995, Julien 1993, Spurling 1992, inter alia). Apoyándome en esas investigaciones pioneras, pero sobre una base documental mayor (Ramón 2008a: 94-131), apuntaré al escenario colonial temprano. Antes que panoramas, tenemos fragmentos, y cabe recalcar que la información sobre áreas con relativa riqueza documental como la sierra limeńa o la Costa Norte, no es necesariamente generalizable para todos los Andes ${ }^{8}$.

\subsection{El impacto colonial}

Dos testimonios nos introducen a la actividad alfarera en los albores del régimen colonial. En primer lugar, se debe mencionar el registro de los quipucamayoc de los tambos de Jauja al paso 
de Francisco Pizarro en 1533. En esas instalaciones imperiales se consignaron 55 cántaros, ollas, puños [puỹü] y tinajas (vasijas medianas y grandes) y 1316 chamelicos, porongos [purunku] y escudillas (vasijas pequeñas). Ese mismo año también se «ranchearon» 1231 cántaros y 11285 porongos. El quipu prosigue registrando los objetos almacenados hasta el paso de La Gasca hacia 1548. Este documento evidencia una especie de inercia de la maquinaria estatal inca: pese a la caída del Tahuantinsuyu los alfareros continuaron produciendo vasijas para estos tambos, que siguieron siendo rancheados (Murra 2002: 160, 253). En segundo lugar, meses después de los saqueos en Jauja, Pizarro llegó al Cuzco. Entonces, uno de los señores lupaca, Martín Cari, abandonó esa ciudad y fue hasta Milliraya (Puno), el principal centro de producción alfarera y textil del imperio. Al llegar, Cari alertó a los cientos de artesanos (mitimaes) presentes «hermanos ya no es tiempo del ynga agora y os podeis boluer a vuestra tierra cada uno». ${ }^{9}$ Como muestra el litigio donde se incluye este testimonio, algunos artesanos siguieron el consejo de Cari retornando a sus pueblos, otros no ${ }^{10}$.

Así como los tambos de Jauja almacenaron miles de vasijas de cerámica, Milliraya formó parte de una red de centros productivos imperiales. En el caso del enorme taller inca de Shultín (Cajamarca) algunos alfareros desplazados desde la costa para servir en ese emplazamiento serrano volvieron a sus tierras en el curacazgo de Collique (cerca de Chiclayo), y el curaca de la waranga de Guzmango (Cajamarca) trató de quedarse con los artesanos restantes en su jurisdicción. ${ }^{11}$ Aunque los alfareros pudieron seguir ejerciendo su oficio (en su pueblo de origen, en el lugar donde habían sido desplazados para servir al inca o en un tercer emplazamiento), la maquinaria estatal que los organizaba colapsó.

Esquemáticamente podemos distinguir cuatro niveles iniciales en la producción cerámica colonial temprana. Primero, algunos alfareros locales que pudieron continuar ejerciendo sus labores, han sido identificados en diversos reportes coloniales, por ejemplo en Ichoc Huaraz (Áncash), Chupachu (Huánuco) y Urinsaya (Coporaque, Arequipa) (Fig. 3) (Ramón 2008a: 110, 112-116). Segundo, se encuentran alfareros mitimaes, como aquellos identificados en el extremo sur del callejón de Huaylas (Áncash). Dos linajes de alfareros fueron localizados entre los cinco ayllus del pueblo de San Ildefonso de Recuay. El inca había desplazado a estos artesanos [«camayos y olleros», "Olleros mitimaes»] desde los poblados de Pararín y Pira (ambos en Áncash). De Pararín, los alfareros habían llegado a Recuay dos generaciones antes de la invasión española; de Pira, solo una. En Recuay, los hijos estaban sucediendo a sus padres en las labores alfareras (Hernández Príncipe 2003 [1622]: 763-764, 776). En tercer lugar, se encuentran los pueblos intermedios que aglutinaban artesanos locales. Un caso de este tipo era el pueblo de alfareros de Achim en Canta (sierra norte de Lima), que, en 1549, ya había sido abandonado ${ }^{12}$. Asimismo, entre las cuatro waranqa de los Chupachu (Huánuco), las autoridades españolas identificaron tres emplazamientos similares, denominados «pueblos de alfareros». En dos de ellos trabajaban artesanos de las cuatro waranqa: Acochacha (nueve casas, diez alfareros) y Payna (ocho casas, siete alfareros y tres viudas). Eran mitmaq. El tercer poblado, Cachuchu (dieciocho casas, trece alfareros y cuatro viudas) estaba bajo control político Chupacho, pero reubicado en territorio Yaro (inmediatamente al sur, también en Huánuco) ${ }^{13}$. Estas agrupaciones de carácter imperial fueron las más afectadas por la invasión europea. Finalmente, a un cuarto nivel, la evidencia más impactante proviene de la parcialidad Hanansaya del poblado de Santiago de Coporaque (Arequipa), donde la «visita» de 1616 registra un Ayllu de los Ofiçiales Olleros: 30 alfareros en edad de tributar con sus respectivas familias y 16 unidades residenciales de viejos y menores $(\mathrm{n}=101)$. Sin embargo, si revisamos las notas al margen del documento (probablemente agregadas en 1645, Robinson 2006: XLVIII), más del noventa por ciento de la gente de Hanansaya había muerto. Además del principal, solo cuatro adultos estaban vivos; y el resto, ausente. En la primera mitad del siglo diecisiete, este ayllu de olleros oficiales trasladado a Coporaque era un Comala ${ }^{14}$.

\subsection{Tipos y tiempos}

Considerando la documentación y la literatura disponibles, se pueden distinguir hasta cuatro tipos de alfareros para el Horizonte Tardío (local, mitayoc, mitmaq, yana) según el lugar de producción, 


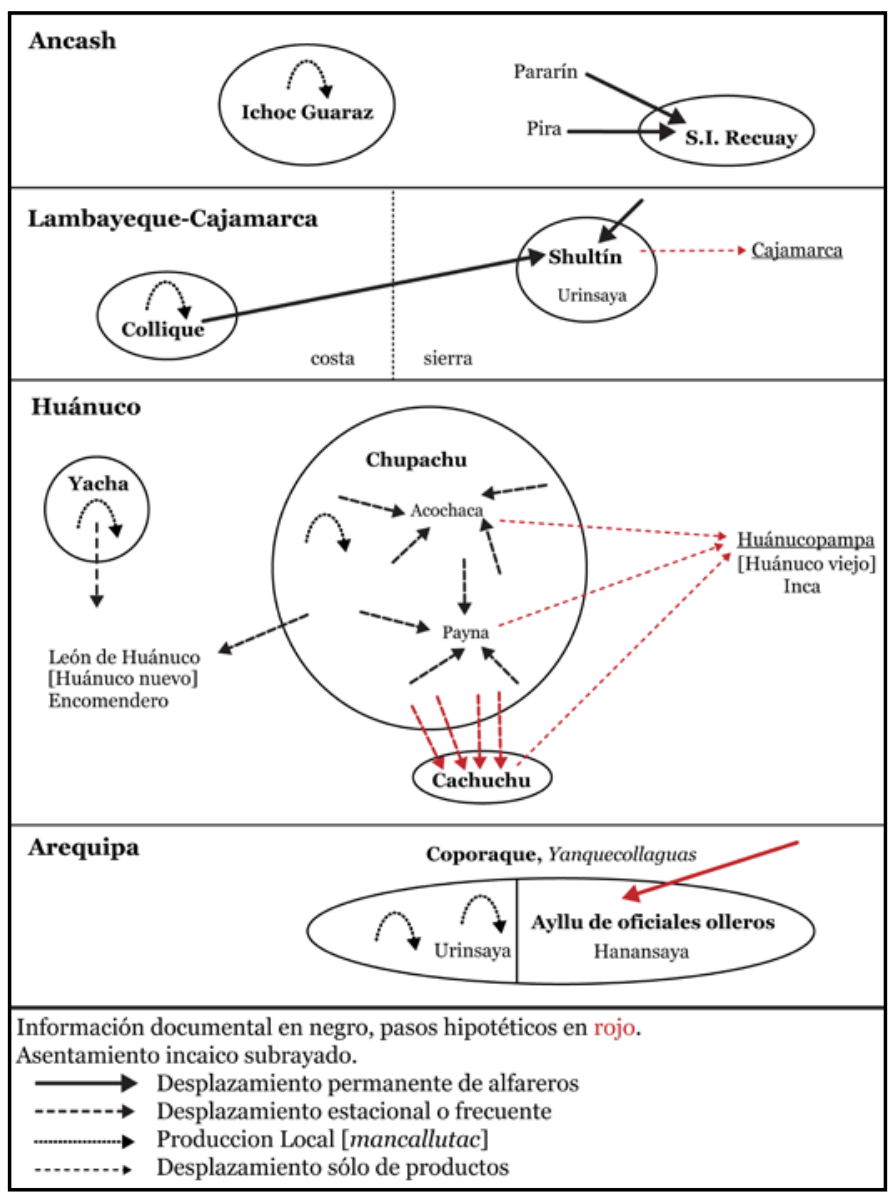

Figura 3. Algunos modelos alfareros en fuentes coloniales tempranas (Diagrama: Gabriel Ramón).

el tipo de supervisión al que estaban sujetos, y el estilo empleado. Considerando estos rasgos diagnósticos podemos dividirlos en dos grupos mayores, el sañucamayoc [oficial de la vajilla o de la arcilla] y el mancallutac [el que hace ollas] (Tabla 2). Con fines comparativos, el primero sería la expresión inca del ollero vinculado con el centro de producción oficial. El mancallutac sería el ollero local, distante de los talleres oficiales o independiente ${ }^{15}$. Desde inicios del régimen colonial el sañucamayoc, relacionado con el poder inca, empieza a desvanecerse como categoría. Mientras tanto el mancallutac perdura con sus actividades productivas en su pueblo y alrededores. Etnográficamente, en los Andes solo se han encontrado mancallutac (Ramón 2008a: 104, n. 9; Matayoshi 1988), aunque es posible distinguir diversos tipos de organización entre estos alfareros.

Para la Costa Norte colonial temprana, hay una distinción complementaria, según los productos elaborados (cerámica fina y llana). Entre los primeros, estarían los mencionados olleros de Collique desplazados como yanayaku al centro de producción inca de Shultín (Cajamarca) y los alfareros que trabajaban para señores locales del litoral. En la segunda categoría, estarían alfareros como los de Jequetepeque, que "hasta agora hemos tenydo costumbre de hazer tinajones grandes e medianos...» ${ }^{16}$. Esta distinción resume una ecuación vigente entre arqueólogos. Por un lado, se encuentran los alfareros que producen vasijas decoradas (emblemáticas) trabajan bajo control político directo; por otro, aquellos dedicados a las vasijas llanas, que tienen otro tipo de público, otras estrategias de supervivencia, y no necesariamente producían bajo control directo. Es esa la distinción señalada por los términos sañucamayoc y mancallutac, que deben entenderse como extremos formales de un espectro ${ }^{17}$. 


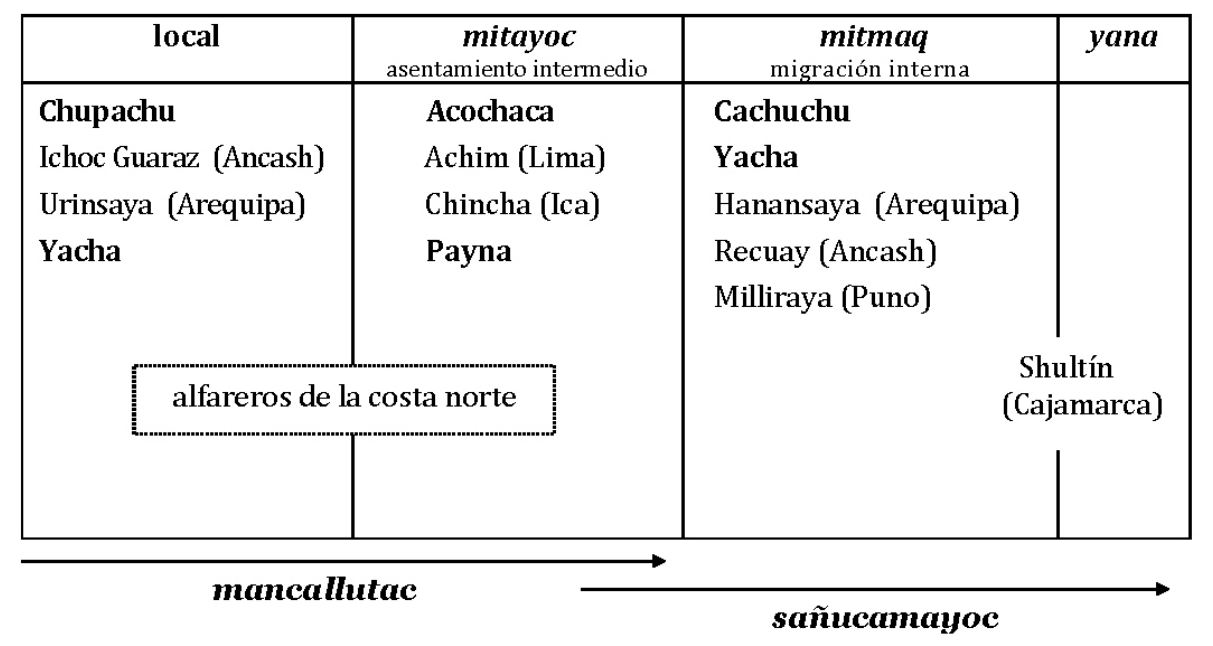

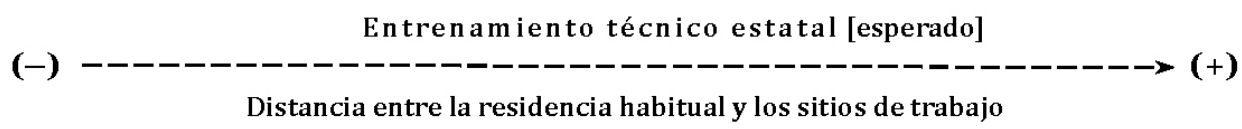

Tabla 2. El sañucamayoc y el mancallutac: desplazamiento y categorias de alfareros. Los alfareros de la Costa Norte eran locales pero aparentemente vivian agrupados con sus colegas, por tanto se aproximaban al trabajo colectivo propio de los mitayoc. Los casos localizados en Huánuco en negrita. Todos los ejemplos están mencionados en el texto.

Aludiendo a una serie de estudios etnohistóricos y etnográficos (Janusek (1999: 110) propuso la categoría de embedded specialization para explicar la producción alfarera en Tiahuanaco (AD 700-1000). Esto implicaría que los artesanos no estaban directamente asociados a las élites, pero tampoco eran completamente independientes (Janusek 1999: 125-127) ${ }^{18}$. Posteriormente Wernke (2013: 102-103, 242-243) ha seguido esa propuesta para los alfareros registrados en Coporaque. Este esfuerzo por establecer categorías intermedias (entre los extremos planteados por autores como Costin 2001) coincide con la orientación general de nuestra investigación. Sin embargo, cabe indicar que la exploración de las fuentes coloniales tempranas sobre alfareros realizada por Janusek y Wernke es mínima, por lo que no inciden en la diversidad de tipos de alfareros que actuaban simultáneamente en ese periodo. Es preciso insistir en esa variabilidad antes de realizar proyecciones analógicas al periodo precolonial. Para organizar esas múltiples categorías de artesanos en relación con el poder inca y el colonial, conviene pensarlas en términos de estilos externos e internos.

\subsection{Perspectivas estilísticas}

Los incas tuvieron un conjunto de formas oficiales, impusieron un estilo externo imperial, que precisamente hace posible reconocer su cerámica en el registro arqueológico (Rowe 1944: 48). También es posible observar que incluso estas vasijas oficiales fueron producidas usando estilos técnicos locales. Así, en la Costa Norte peruana aparecen recipientes elaborados con doble molde horizontal: encontramos urpu con decoración y forma inca, pero con la marca central producida por la unión de los moldes (Hayashida 1995: 230). Hacia el sur, en Ica, la descomposición imperial permitió el resurgimiento de los estilos decorativos locales, los llamados arcaismos, materialización de «micro-nacionalismos» (Menzel 1960). El estilo decorativo inca y sus sañucamayoc acompañan al imperio en su ocaso. Es sobre este palimpsesto estilístico y social que se asentó el régimen colonial. Cabe recordar que el propio imperio inca había generado una compleja red estilística, como 


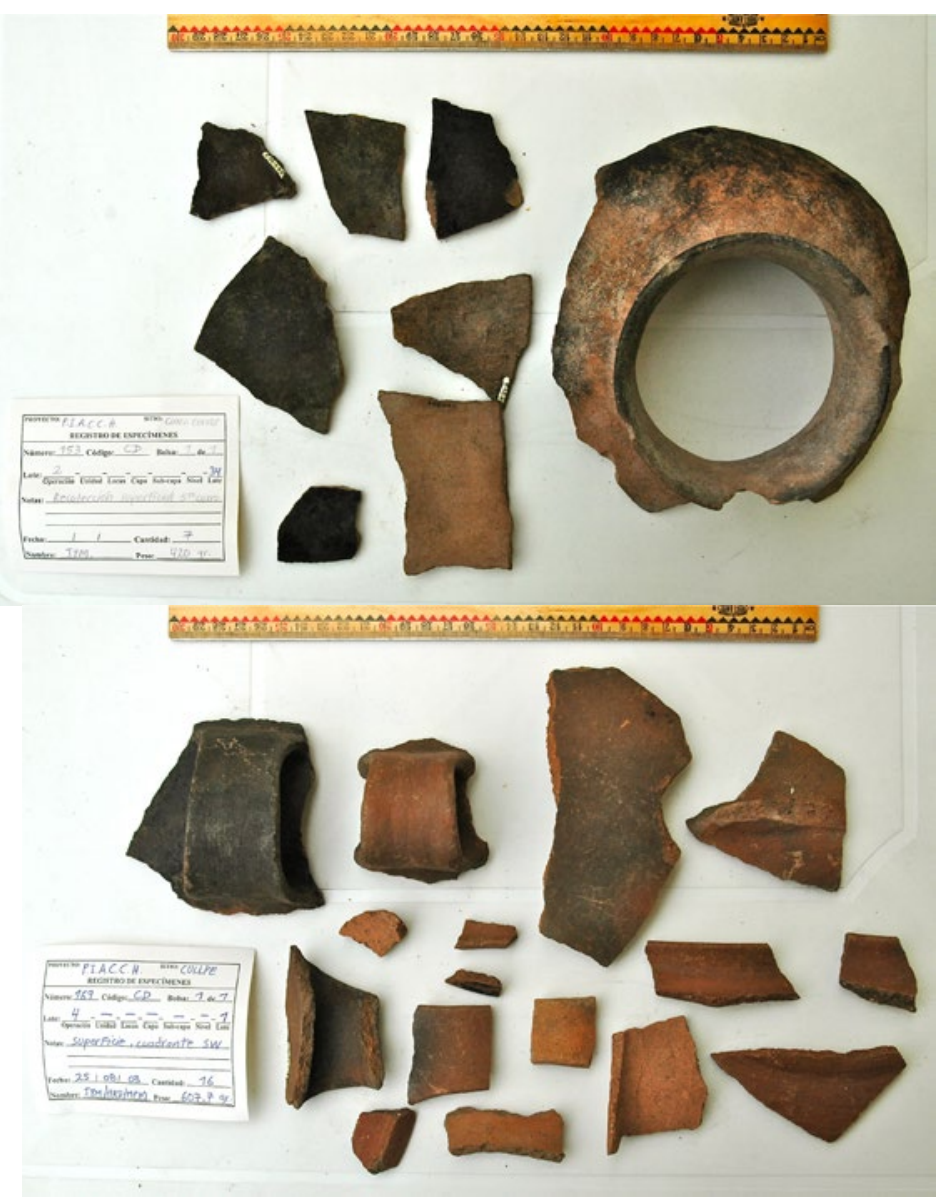

Figura 4. Cerámica de los sitios de Cinco Cerros y Cullpe (Huarochirí, Lima). En muchos casos es técnicamente imposible determinar si se trata de cerámica colonial o precolonial (Excavaciones 2003, PIACCH). Escala $30 \mathrm{~cm}$.

aquellas vasijas chimú/inca/ichma halladas en Pachacamac (Lima), probablemente, elaboradas por alfareros norteńos desplazados a la costa central (Feltham y Eeckhout 2004: 666, 668). Una buena imagen de la dinámica coyuntura colonial temprana son las vasijas chimú/inca/vidriadas, que nos incitan a pensar en diversos niveles de interacción espacial y política: ¿eran alfareros de filiación étnica chimú entrenados por los sañucamayoc inca y trabajaban en contextos coloniales urbanos? (Mayer 1983, Bushnell 1959). Una complejidad semejante es sugerida por el famoso dibujo de Juan Capcha con la botija (de filiación hispana) en una mano y el urpu en la otra (Guaman Poma 1980[1615]: 790, 791).

Tenemos, entonces, un panorama básico de lo sucedido con los estilos decorativos al iniciar el régimen colonial, pero sabemos muy poco de lo que pasó con su contraparte, los estilos técnicos. En el registro arqueológico y en los depósitos de los museos, hay múltiples vasijas sobre las cuales no es posible decidir si son precoloniales tardías o coloniales tempranas (Figs. $4 \mathrm{a}$ y $4 \mathrm{~b}{ }^{19}$. A diferencia de lo sucedido con la decoración, más sensible a los cambios políticos, no hubo necesidad de arcaísmos técnicos en la época colonial temprana, debido a que los estilos técnicos tradicionales preincas no habían desaparecido durante el Tahuantinsuyu: todo indica que los alfareros locales y mitayoc como los que trabajaban en pueblos intermedios (Achim o Acochaca) no fueron compelidos a cambiar de estilo técnico. Así como el vidriado es un rasgo diagnóstico del estilo decorativo colonial (lo usamos en arqueología), el torno alfarero sería su contraparte (v.g. rasgo diagnóstico del estilo técnico colonial). 
Sin embargo, el torno se mantuvo restringido a centros de producción urbana, sin dejar rastro considerable en el campo. En este sentido, debemos recordar que las famosas instrucciones del virrey Toledo (1986 [1569-75]I: 465) van contra la decoración de los objetos muebles e inmuebles, contra su estilo externo, sin incidir en sus estilos técnicos: "Que no labren figuras en las ropas ni en vasos ni en las casas. -Por cuanto los dichos naturales también adoran algún genero de aves y animales y para el dicho efecto los pintan y labran en los mates que hacen para beber de palo y de plata y en las puertas de sus casas, ordeno y mando que los que halláredes que los hagáis derribar y quitar de las puertas donde estuvieren y prohibiréis que tampoco los tengan en la ropa que visten $»^{20}$.

Esta disposición de Toledo insiste en decoración no en el modo de manufacturar los objetos. Sin embargo, un fraile, Martín de Murúa, a inicios del siglo XVII, percibió la importancia simbólica del estilo técnico, pero se concentró en la manufactura de textiles, y desconocemos si llegó a implementar medidas concretas (Desrosiers 1986). Sintetizando dos facetas de la actitud colonial, en ambos casos (Murúa, Toledo), el estilo técnico alfarero pasó desapercibido y Guaman Poma se mantuvo significativamente silencioso sobre los procesos productivos de objetos (Cummins 1997). En suma, podríamos afirmar que a las autoridades coloniales no les interesó alterar las técnicas de manufactura alfarera rural: mientras para otros aspectos productivos (pensemos en las herramientas asociadas al trigo) se introdujeron artefactos europeos, en el campo se siguieron elaborando vasijas con estilos técnicos empleados en tiempos precoloniales, incluyendo o no decoración colonial.

\subsection{La red urbana}

Volviendo al desolado ayllu de oficiales olleros de Coporaque (Arequipa), conviene indicar que no todas las localidades mayoritaria o exclusivamente constituidas por alfareros tuvieron la misma suerte. Por ejemplo, en una visita de fines del XVII a Piura se consigna que el pueblo con alfareros de Sondor (Huancabamba, Piura) estaba en plena actividad (Loayza 2006 [1573]: 276), rasgo que mantuvo hasta el presente (Ramón 2008b: 490-492). En general, podemos afirmar que, si bien el estado colonial no parece haber intervenido en las técnicas de manufactura de los alfareros locales, si se interesó por su localización. Establecimientos análogos al ayllu de olleros oficiales de Coporaque fueron (re)fundados en diversas partes de los Andes, varios de ellos incluyeron el apelativo «olleros» (uno en Amazonas, uno en Áncash, dos en Lima, uno en Piura). Los detalles sobre la composición inicial de estos pueblos son opacos, aunque es probable que, en algunos casos, como Santo Domingo de los Olleros, se aprovechara grupos de artesanos preexistentes (Miasta 2006: 37-39, Ramón 1999).

Antes de pasar a nuestros tres ejemplos plenamente coloniales, volvamos a los alfareros mencionados en la visita de Huánuco que ilustran la transición. Este documento contiene el más completo de los testimonios coloniales tempranos, que contempla la diversidad de productores de vasijas mencionados. Además de incluir tres de los casos inca (alfarero local, mitayoc y mitma) hay un grupo adicional, ilustrativamente colonial, con al menos cuatro integrantes. Primero, se encuentra un alfarero que trabajaba un mes al año para el encomendero en la ciudad de Huánuco, haciendo ollas, ladrillos y tejas. Él debía formar parte de los «ocho tejeros y olleros» asignados a esa autoridad. Segundo, un alfarero mudo que solo hacía ollas grandes para teñir ropa como parte de su tributo. Tercero, un «oficial ollero» desempleado y, finalmente, un ollero que había huido de su aldea, lugar al que retornó luego de la visita. Este grupo de artesanos materializa la impronta de las ciudades y las reducciones en el medio rural andino. Como veremos, los alfareros se vincularon a la urbe de diversas formas.

\section{Materializar las redes de producción y circulación}

La cerámica es un elemento ubicuo en el registro arqueológico colonial temprano; sin embargo, la información documental sobre sus productores es mínima. Hemos escogido tres casos de este periodo, ya que muestran el impacto del régimen colonial y permiten articular varios puntos de la cadena operativa alfarera. 


\subsection{Primer caso: alfareros itinerantes (Costa Norte)}

La documentación generada durante el régimen del oidor Gregorio González de Cuenca (especialmente en los 1560) ha servido de base para caracterizar la organización sociopolítica de la Costa Norte precolonial tardía y colonial temprana (Netherly 1977, Noack 1996). Como sabemos este funcionario deseaba que los artesanos continuaran con sus actividades para hacer posible el funcionamiento del sistema, por lo cual sus reportes incluyen detalles sobre estos oficios. En esas zonas se identificaron alfareros en los curacazgos de Collique (1566), Jayanca (1540), Pacasmayo (1566), Sinto (1566) y Túcume (1566) (Ramírez 2007: 264). Hay un rasgo presente en estos testimonios norteños que ha sido soslayado entre historiadores: la movilidad consuetudinaria de oficios hoy asumidos como sedentarios. En ese sentido, hay un caso particularmente atractivo ya que permite vincular tipología y localización planteando la posibilidad de modelos más dinámicos de alfareros coloniales tempranos. Se trata de la solicitud del ollero Toy del curacazgo de Collique (cerca de la ciudad actual de Chiclayo) y cinco colegas suyos: pidieron ser eximidos de la mita y que no se les impusiesen límites espaciales para ejercer su oficio. Al conceder la licencia a estos alfareros hay un pasaje revelador: "Y por Su Merced vista dio licencia al dicho indio Toy e a los demas indios olleros aqui declarados para que libremente puedan ir o vayan a cualesquier repartimientos a usar sus oficios y llevar o vender las obras dél sin que los caciques e principales e indios ni otra persona se lo tome ni quite [...]» (énfasis agregado) ${ }^{21}$.

Hace buen tiempo, los etnógrafos han reconocido a los alfareros vendedores itinerantes; sin embargo, hay una categoría distinta, que, pese a ser frecuente en los Andes, es poco conocida: los alfareros productores itinerantes o golondrinos (Ramón 2008a: 232-261; 2011, 2013). Precisamente, el documento citado alude a «ir...a usar sus oficios», es decir, desplazarse para fabricar vasijas de cerámica a otras localidades, además de llevarlas y venderlas. Hay dos elementos complementarios. En primer lugar, como indicamos anteriormente, para esta misma zona fueron reconocidos alfareros especializados en hacer vasijas llanas grandes, los tinajones; por su dificultad para ser desplazados, es más simple que hayan sido elaborados in situ (Sillar 2000: 91-92; Rice 1996: 798; Peacock 1982: 27). En segundo lugar, el curacazgo de Collique está en el radio de acción de dos importantes centros alfareros caracterizados por sus actividades itinerantes: el ámbito simbileño (con su centro en Piura) y el ámbito mangallpino (con su centro en Cajamarca), ambos con estilos técnicos ligeramente distintos (Ramón 2011: 167-168; 2013: 77-87). Concomitantemente, este tipo de alfareros ha sido sugerido para explicar la producción de las grandes vasijas domésticas chimú, Intermedio Tardío (Prieto 2008). La visita de González de Cuenca permite iluminar la hipótesis golondrina para el Periodo Colonial Temprano, que desestabiliza las restrictivas unidades histórico-culturales, y sobre todo el mito del alfarero consuetudinariamente incrustado en su comunidad, por lo cual sospecho que los arqueólogos precoloniales tardarán en incorporarla como posibilidad habitual al interpretar el material cerámico. Sin embargo, en arqueología colonial tenemos todos los elementos para documentar este tipo de alfareros sin estar atados a compromisos previos.

\subsection{Segundo caso: volver a las canteras (Sierra central)}

Seguidamente, se ilustra la relación entre pueblos viejos, reducciones y canteras de arcilla para ollas. Para el período colonial temprano, hay un litigio entre autoridades religiosas y miembros de un poblado de origen precolonial San Francisco de Callaguaya, algunos kilómetros al suroeste de Santo Domingo de los Olleros (Huarochirí, Lima) ${ }^{22}$. Por información mencionada en el documento, y considerando la localización actual del pueblo, este asentamiento ubicado en la zona quechua baja, inmediata a la chaupiyunga habría resultado de una agrupación oficial inca o colonial temprana (en 1616 se indica «tantos años que están allí») ${ }^{23}$. A fines del siglo XIV, sus habitantes fueron oficialmente desplazados a los pueblos de Huarochirí y San José de los Chorrillos, a más de seis leguas de «terreno áspero», y a mayor altitud, en la zona quechua alta. 
Como este nuevo orden colonial cercenaba sus tradicionales redes de subsistencia, los Callaguaya buscaron una solución retornando a su "pueblo viejo» para «hacer sus chacaras y sementeras y losa de barro» (:1r; énfasis agregado). Ellos intentaron volver periódicamente ya que se sustentaban "con lo que alli siembran maíz, trigo y ollas que alli hacen por ser oficiales dellas [...]» (:14v; énfasis agregado). Asimismo, para consolidar su presencia en el pueblo viejo, este grupo de más de setenta personas había erigido una capilla a su patrono en Callaguaya. El documento revela que se negociaron varias soluciones entre las autoridades eclesiásticas y los curacas. Sin embargo, según el último dictamen (29.XI.1616) los habitantes de Callaguaya debían permanecer en su reducción (Huarochirí) con autorización para volver por un mes cada año para la siembra y otro para la cosecha a su pueblo viejo (:14v). Cabe agregar que este litigio se producía mientras se realizaba la fundación española de Santo Domingo de los Olleros (1613), que aglutinó a los alfareros de la zona ${ }^{24}$. Aunque la conexión puntual entre ambos acontecimientos no ha sido precisada, este documento muestra la compleja relación entre áreas de producción, consumo y canteras de materias primas ante el impacto colonial temprano. Aparentemente, en esta zona de Huarochirí el propio sistema colonial habría provocado una especie de «archipiélago» colonial, con el núcleo residencial en la reducción y algunas actividades productivas, incluida la alfarería, en la nueva periferia (Callaguaya). Este caso también nos permite re-pensar los modelos de producción y distribución alfarera asumidos para la costa-sierra central, particularmente los propuestos para una zona relativamente próxima como Sisicaya (Lurín) (Feltham 2009: 67).

\subsection{Tercer caso: abastecer el centro (Lima)}

Teniendo en mente los dos ejemplos anteriores, conviene ahora remitirse al caso urbano con mayor documentación sobre distribución y producción alfareras. Insistiré en el esquema diacrónico, es decir una cronología orientada a distinguir entre tipos de alfareros y relacionarlos con sus potenciales productos. Una de las primeras referencias sobre alfarería en Lima alude al pueblo de Santo Domingo de los Olleros, Huarochirí. Describiendo la localización de una cantera de piedra bermeja y blanca supuestamente empleada por los indígenas en el sitio precolonial de Pachacamac, se indica "ençima en el rrio de pachacama azia los olleros» (LCL 19.II.1563) 25. Cabe enfatizar el modo genérico como se alude a «los olleros», sugiriendo que eran bien conocidos entre los miembros del cabildo. Todo indica que eran los principales productores alfareros de la zona, y, potencialmente, habrían sido los abastecedores de la ciudad temprana. Una década después, en las actas del cabildo se señala que los cuatro olleros de la ciudad estaban vendiendo la loza (escudillas y platos) a precios excesivos. El problema era que en Lima «ay gran suma de gente pobre como es notorio que comen con laca [loça] y no lo pueden pagar» (LCL 8.VI.1573; énfasis agregado ${ }^{26}$. A inicios del siglo XVII, el cabildo limeño intentó formalizar la distribución alfarera prohibiendo a los regatones de loza. Además de anular a estos revendedores, se buscó fijar el precio "que a de tener todo genero de loça bedriada e por bedrial [vidriar] para los que la hazen que a solo ellos se les permita la bendan» (LCL 3.VII.1606, énfasis agregado) ${ }^{27}$.

La evidencia listada permite sugerir que, concluyendo el siglo XVI, además de la presencia de los artesanos en la zona de Olleros, en la propia ciudad de Lima había producción local de loza vidriada y sin vidriar. En este punto, conviene comenzar a sistematizar la nomenclatura sobre el acabado de los productos alfareros, para relacionar documentos y objetos. Mientras para el citado caso de San Francisco de Callaguaya se menciona «losa de barro», en el LCL se alude a «loça», «loça bidriada», «loça por bedriar». De este modo, podríamos distinguir dos grupos principales: por un lado, «losa de barro», «loça», «loça por vedriar». Por otro, «loça bedriada». El primero no provoca mayor controversia, debido a que este tipo de vajilla fue producida dentro y fuera de la ciudad. El segundo grupo potencialmente debió incluir dos tipos de vidriado (parcial y total) y de mayólica (normal, y falsa) (sensu Acevedo 1986: 22-23). El vidriado resulta de la aplicación de una capa adicional de material (que varía según la región) y puede observarse incluso sobre vasijas de estilo precolonial (chimú/inca/colonial) (algunas ilustraciones en Acevedo 2004: 56-60; Mayer 1983; Bushnell 1959). Sin embargo, la mayólica tiene un proceso más complejo que requiere agregar óxido de estaño a un vidriado de plomo, lo cual da como resultado en una superficie blanca, 


\begin{tabular}{|c|c|c|c|c|c|c|c|}
\hline código & individuo & edad & $\begin{array}{c}\text { lugar de } \\
\text { origen }\end{array}$ & $\begin{array}{c}\text { años en } \\
\text { Lima }\end{array}$ & curaca & encomendero & referencia \\
\hline 1 & $\begin{array}{l}\text { Francisco } \\
\text { Saguay }\end{array}$ & 20 & $\begin{array}{l}\text { Trujillo, } \\
\text { ciudad }\end{array}$ & 7 & $\begin{array}{l}\text { Miguel } \\
\text { Chumbi }\end{array}$ & $\begin{array}{c}\text { tesorero de la Real } \\
\text { Audiencia }\end{array}$ & $: 254$ \\
\hline 2 & $\begin{array}{c}\text { don Francisco } \\
\text { Talabera }\end{array}$ & & Surco & & & & $: 255$ \\
\hline 3 & Juan Caycay & 22 & $\begin{array}{l}\text { Trujillo, } \\
\text { ciudad }\end{array}$ & 6 & $\begin{array}{l}\text { Miguel } \\
\text { Chunqui }\end{array}$ & $\begin{array}{c}\text { tesorero de la Real } \\
\text { Audiencia }\end{array}$ & $: 259$ \\
\hline 4 & Juan Pizarro & 30 & Surco & $\begin{array}{l}\text { "criado en } \\
\text { esta ciudad" }\end{array}$ & Domingo & & $: 327$ \\
\hline 5 & $\begin{array}{l}\text { Hernando } \\
\text { Chirreque }\end{array}$ & 24 & $\begin{array}{l}\text { Túcume, } \\
\text { Trujillo }\end{array}$ & 3 & $\begin{array}{l}\text { Francisco } \\
\text { Mincha }\end{array}$ & $\begin{array}{l}\text { previo L. Camudio/ } \\
\text { actual J. de Ibarra }\end{array}$ & $: 402$ \\
\hline 6 & Benito Tuto & 27 & $\begin{array}{l}\text { Túcume, } \\
\text { Trujillo }\end{array}$ & 1 & $\begin{array}{l}\text { Francisco } \\
\text { Mincha }\end{array}$ & $\begin{array}{l}\text { previo L. Camudio/ } \\
\text { actual J. de Ibarra }\end{array}$ & $: 402$ \\
\hline 7 & Diego Sanchez & 30 & $\begin{array}{c}\text { Túcume, } \\
\text { Zaña }\end{array}$ & 5 & $\begin{array}{l}\text { Francisco } \\
\text { Minchan }\end{array}$ & $\begin{array}{l}\text { previo L. Camudio/ } \\
\text { actual "no sabe" }\end{array}$ & $: 434$ \\
\hline
\end{tabular}

Tabla 3. Alfareros indígenas en Lima, según el Padrón de Indios. La referencias indican la página de Contreras 1968 [1613].

sobre la que se podían realizar dibujos (Goggin 1968: 3). Pese a que las fuentes documentales no son muy detalladas, hay una excepción que permite afirmar que ya se producía mayólica en Lima del siglo dieciséis: en un pleito de 1577 entre la ciudad y los alfareros, estos indican que empleaban plomo y estaño (Harth-Terré y Márquez 1958: 424) ${ }^{28}$.

Realizadas estas precisiones formales, conviene ingresar a la actividad alfarera limeña desde una perspectiva complementaria: el Padrón de indios (Contreras 1968[1613]). En una ciudad con algo más de veinticinco mil habitantes, se registraron casi dos mil indios (1287 hombres, 630 mujeres), incluidos siete alfareros (Tabla 3). Se alude también a dos españoles, Juan de la Torre y Francisco de Ponte (Contreras 1968[1613]: 327, 347). Todos los alfareros indígenas son denominados oficiales olleros, salvo los hermanos Hernando Chirreque y Benito Tuto, solo olleros («se ocupan en hacer ollas»). Don Francisco Talabera, indígena, solo es mencionado indirectamente. En general, los alfareros son hombres, jóvenes, nacidos fuera del centro de Lima (cinco en Trujillo, dos en Surco), pero residentes en la capital. Técnicamente, tres de los trujillanos son de Túcume, relativamente próxima al escenario donde laboraban Toy y sus colegas (ver Primer caso). El Padrón contiene algunos indicios sobre el proceso de entrenamiento urbano, por ejemplo, se seńala que el alfarero indígena Juan Pizarro, de Surco, vivía en "casa de su maes[tr]o", el español Juan de la Torre, y "le sirve por carta", es decir tienen un contrato de aprendizaje (Harth-Terré y Márquez 1963: 359, 435). Pese a estar viviendo en Lima, los alfareros trujillanos mantenían vínculos con su territorio natal. Primero, tres $[5,6,7]$ estaban casados con mujeres de su lugar de origen (Túcume), quienes seguían residiendo allí. Segundo, los cinco mencionaron a alguna de sus autoridades locales (curaca o encomendero).

El censo de 1613, realizado luego de registrar más de tres mil viviendas y tiendas en la ciudad de Lima muestra que, además de los potenciales productos de Santo Domingo de los Olleros, parte de la producción local limeña estaba en manos de artífices foráneos — especialmente, norteñosque no habían perdido sus lazos locales. Dos testimonios complementan el panorama sobre producción y circulación alfarera. 


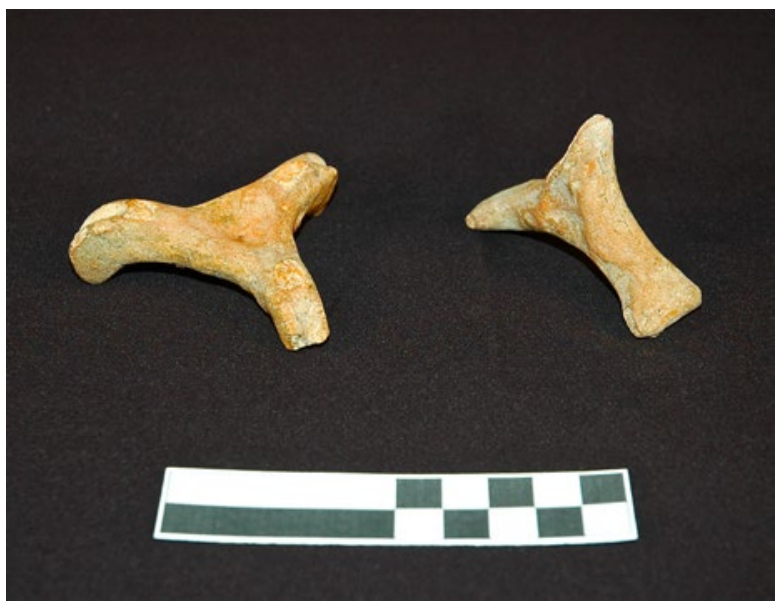

Figura 5. Tripodes, Lima (en la caja se indica "Rescate Av. Roosevelt, J[uan] M[ogrovejo] R[osales]", Museo Josefina Ramos de Cox, Instituto Riva Agüero, PUCP). Escala $10 \mathrm{~cm}$.

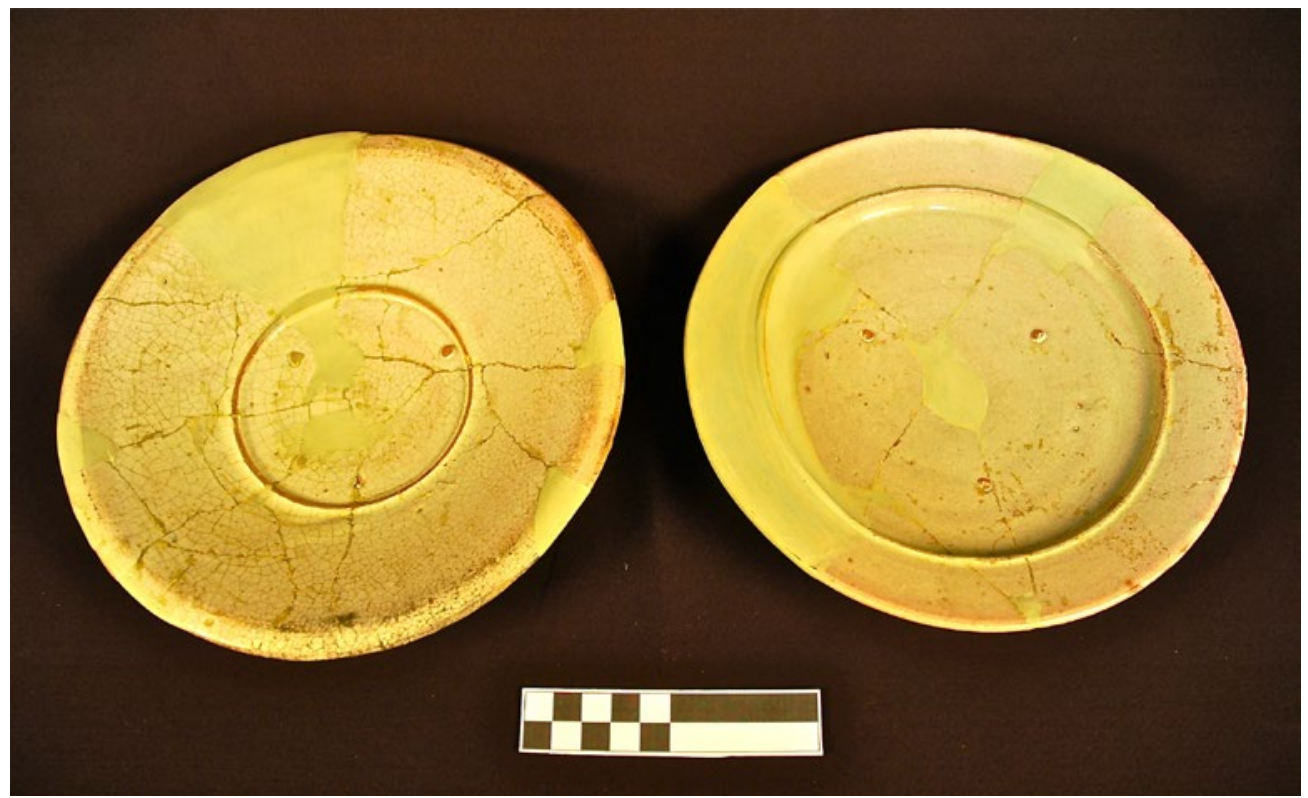

Figura 6. Platos vidriados con marcas de trípode, Huaca Tres Palos, Lima (código: 01954 a-b, Museo Josefina Ramos de Cox, Instituto Riva Agüero, PUCP). Escala $10 \mathrm{~cm}$.

Al realizar el recuento de las actividades comerciales capitalinas, Salinas y Córdova (1957 [1653]: 256) consignaba: «Olleros siete tiendas», sin especificar si eran solo sitios de venta o también talleres, ni el tipo de producto expendido. Probablemente se refiera a productores-vendedores (como en LCL 3.VII.1606). Este cronista también alude a la circulación de productos cerámicos. Primero, mencionaba que entraban a Lima «indias cada dia, con tinajones, y ollas grandes de locros», es decir recipientes de comida probablemente producidos en el área rural (Salinas 1957 [1653]: 253). Segundo, señalaba «Entran muchas canastas, y bateas de losa, vidrios, y muchas suertes de barro pintado, y vedriado de la tierra, y fuera della; de Ica, de Guamanga, del Cuzco, de Panama, de la China, de Portugal, de Benecia, y de Viscaya» (Salinas 1957 [1653]: 254; énfasis agregado). Salinas está describiendo un modelo abierto de circulación y producción alfarera para Lima. Por un lado, 


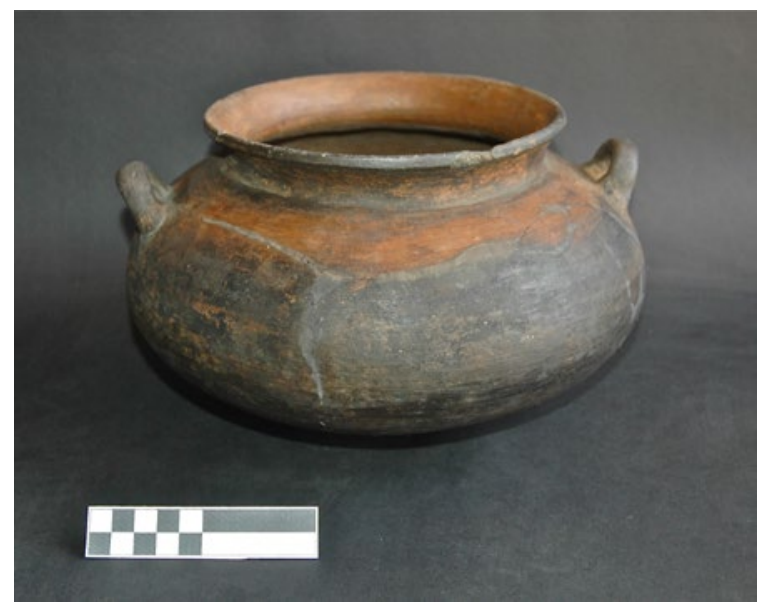

Figura 7. Vasija tipo Santo Domingo de los Olleros, encontrada en un contexto colonial del centro de Lima (Proyecto Arqueológico Bodega y Quadra, EMILIMA, Municipalidad de Lima). Escala $10 \mathrm{~cm}$. La olla ha sido restaurada.

como vimos, había olleros indígenas y españoles en la ciudad. Por otro lado, también, se importaban vasijas, incluidas pintadas («barro pintado») y vidriadas «de la tierra, y fuera della». Esto último indicaría recipientes producidos en otras partes del Perú (Cuzco, Guamanga, Ica) y más allá (China, Panamá, Portugal, Venecia, Vizcaya).

Si bien el testimonio de Salinas describe bien la circulación hacia Lima y el virreinato peruano, el jesuita Bernabé Cobo tiene notables observaciones sobre producción. Primero, indicaba la manufactura de loza en la ciudad de Cuzco y la provincia de Chucuito, y más cerca a Lima, en Ica al sur y Supe al norte (Cobo 1890 [1653]: I: 240) (sobre Ica $c f$. Vázquez de Espinoza 1968 [1620]: 484). Segundo, Cobo observaba que en el virreinato peruano se hacía «tan escogida loza y tan bien vidriada, que no hace falta la de Talavera [España]». Incluso, se había comenzado a "contrahacer la de China, y sale muy parecida á ella, particularmente la que se hace en la Puebla de los Ángeles en la Nueva Espańa y en esta ciudad de Lima, que es muy buena y de lindo vedrio y colores. Asimismo, se elaboraban «muy curiosos azulejos, que antes se solían traer de España; si bien es verdad que no salen los de acá de tan finos colores» (Cobo 1890 [1653]: I: 243, énfasis agregado). Es decir, en el virreinato peruano se elaboraban objetos semejantes a aquellos de los principales centros productivos vinculados al Imperio hispano: azulejos, mayólica tipo Talavera y vasijas tipo China ${ }^{29}$. Los testimonios anteriores muestran la necesidad de emplear un modelo abierto para Lima y plantea una interrogante aún vigente entre arqueólogos: ¿Cómo distinguir productos locales y foráneos? En concreto, ¿cómo saber que un fragmento de mayólica hallado en una capa colonial de Lima es foráneo (de cualquiera de las diversas variedades) o local imitando lo foráneo («contrahecho»)?

La diversidad de material arqueológico reportado en la literatura sobre Lima, y aquel depositado en almacenes y museos de esa ciudad confirma el panorama presentado por las fuentes históricas citadas (Cobo 1890 [1653], Contreras 1968 [1613], LCL, Salinas 1957 [1653]). Vayamos entonces desde la distribución a la producción. Primero, el componente alfarero de los sitios coloniales limeńos destaca por la diversidad de productos: cerámica no vidriada («losa de barro»), vidriada por el interior (loza vidriada), vidriada por ambos lados (loza vidriada), mayólica (loza vidriada), loza china, entre otros [distribución]. Segundo, en varios sitios arqueológicos de Lima se han encontrado diversas vasijas con huellas de problemas técnicos durante la manufactura, o más precisamente durante la quema (pintura deslizada, piezas sobre cocidas, marcas del trípode, etc.). Estas evidencias estarían indicando manufactura local, ya que se asume que las vasijas falladas no circulan muy lejos de su centro de manufactura [producción] ${ }^{30}$. Tercero, se han hallado artefactos asociados a la quema, como los trípodes para separar las piezas durante la cocción (Fig. 5) y sus huellas en las vasijas (Fig. 6) ${ }^{31}$. Cuarto, para 1630, en el inventario de bienes de un mercader 
se consigna la presencia en Cuenca (Ecuador) de vajilla fina producida en Lima (Paniagua y Truhan 2003: 558). Quinto, recientemente identificamos al menos una vasija hallada en un sitio colonial a dos cuadras de la Plaza Mayor, formalmente similar a aquellas producidas en la sierra limeńa, en Santo Domingo de los Olleros (Fig. 7). La localización urbana de esta vasija es importante. Por un lado, refuerza la hipótesis deducida de la temprana mención a los olleros por las autoridades del cabildo (LCL 19.II.1563): la presencia de vasijas serranas en el núcleo urbano de la capital. Por otro lado, aunque se trata de evidencia todavía muy limitada, abre una serie de interrogantes sobre las relaciones entre producción urbana y rural, sugeridas también por las evidencias documentales ${ }^{32}$. Para concluir, conviene sintetizar en perspectiva el proceso descrito.

\section{Reflexiones finales}

La descomposición del Tahuantinsuyu provocó el fin del estilo decorativo asociado a este imperio, mientras tanto, los estilos técnicos que se venían practicando siguieron en vigencia, en manos de los mancallutac convertidos en olleros coloniales. Ni para el estado incaico ni para su contraparte colonial, los estilos técnicos cerámicos habrían sido objeto de particular interés. Sin embargo, ambos estados se preocuparon por la localización de los conglomerados de alfareros, que varió en relación con los centros de poder respectivos. Generalmente, a medida que los grandes asentamientos de poder inca fueron abandonados, sus centros asociados de producción alfarera se desarticularon, como en los citados ejemplos de Huanucompampa y Milliraya. Sin embargo, en ciertos casos los lugares de prestigio colonial se ubicaron relativamente próximos a centros precoloniales importantes, lo cual favoreció la permanencia de producción especializada, como parecería haber sucedido con el área ocupada por el pueblo colonial de Santo Domingo de los Olleros. Este triángulo geográfico e histórico (Olleros/Pachacamac/Lima) ha generado tal cantidad de información documental y material, que permite abordar temas rutinariamente soslayados de la historia colonial temprana.

Siguiendo la tradición establecida por sus colegas dedicados a lo precolonial, los arqueólogos e historiadores del arte que lidian con cerámica colonial suelen limitarse a aquella decorada. Tradicionalmente, este tipo de detalle permitió atar más cabos sobre el ciclo vital de las vasijas, por ejemplo, podemos indicar su estilo decorativo y sugerir su lugar de producción. Sin embargo, sabemos poco del universo de vasijas llanas como la que hemos atribuido tentativamente a Olleros, por su morfometría. Afortunadamente, la tradición constante de estudios sobre esta zona ha permitido que incluso su cerámica doméstica resulte informativa, es decir potencialmente historiable ${ }^{33}$.

$\mathrm{Si}$ intentamos conciliar la evidencia presentada para Lima (circulación desde diversos puntos, producción local diversificada, interacción de alfareros indígenas y españoles), con los otros dos casos de esta última sección (producción itinerante, movimiento de los alfareros hacia sus canteras) debemos ampliar el panorama habitualmente asumido para explicar la producción y circulación alfarera colonial en la capital del virreinato peruano, siguendo un modelo abierto. En este contexto, la mencionada vasija tipo Santo Domingo de los Olleros complejiza el asunto del lugar de manufactura y sugiere interrogantes sobre la relación entre el centro urbano de Lima y su hinterland, específicamente Huarochirí: ¿Este tipo de vasija fue producido en Olleros y traído a la ciudad, o elaborado por alfareros olleranos en Lima? El cuestionario se ampliaría considerando la proveniencia de la materia prima (¿de la sierra?, ¿de los alrededores de Lima?, ¿combinada?). Todas son posibilidades histórica y etnográficamente documentadas para los Andes; por tanto, no descartables a priori.

Como sabemos las vasijas no decoradas constituyen la amplia mayoría de recipientes producidos y distribuidos en los Andes coloniales; por ello, tanto debemos considerarlas en nuestra explicación. Surge entonces una serie complementaria de interrogantes sobre patrones de consumo: ¿Cómo estaba compuesta la vajilla usada en las viviendas de Lima? (de la "gran suma de gente pobre» y de los vecinos)?, ¿dónde fue producida esta vajilla?, ¿cómo distinguirla? A juzgar por los hallazgos realizados en Lima, puede afirmarse que se trataba de una vajilla mixta, es decir provenía de múltiples centros de producción (desde China hasta Olleros, incluido Panamá, además de la producción urbana local). 
Es muy temprano para sugerir pesos específicos en nuestra respuesta ya que ningún proyecto de excavación o de análisis de material colonial ha respondido sistemáticamente a estas interrogantes. Sin embargo, sabemos que para mediados del siglo dieciocho la presencia de los alfareros de Olleros en los alrededores de Lima ya es contundente, principalmente hacia la zona de la parroquia de Santa Ana y el Cercado (O’Phelan 2001; Harth-Terré 1986: 352-353).

\section{Agradecimientos}

Este trabajo ha recibido el apoyo de la Dirección de Gestión de la Investigación de la PUCP, a través de la subvención DGI 2016-1-299. Martha Bell por la cartografía. Miguel Fhon, director del proyecto Bodega y Quadra (EMILIMA), por las ilustradoras visitas y explicaciones sobre el complejo sitio arqueológico a su cargo y por permitirme fotografiar su material. Milagritos Jiménez, curadora del Museo Josefina Ramos de Cox (PUCP), por permitirme fotografiar el material de esa colección, y por facilitarme la información pertinente. José Luis Pino por permitirme reproducir cerámica del Proyecto Cinco Cerros (PIACCH). Mis alumnos del curso de Arqueología Colonial (PUCP y Universidad de Leiden) contribuyeron a discutir algunos de los temas aquí incluidos. A Juan Castañeda por indicarme que había, al menos, un «ollero de Talavera» en el ARLL. Jack Chávez por sus valiosas notas sobre tipos de cerámica colonial. A Abel Traslaviña por su paciencia.

\section{Notas}

${ }^{1}$ Estas páginas forman parte de una historia de los alfareros coloniales, especialmente de Santo Domingo de los Olleros (Huarochirí, Lima). Se nutren de mi trabajo etnográfico en esa localidad (Ramón 1999), y en más de 40 pueblos con alfareros de los Andes septentrionales peruanos, entre Áncash y Piura (Ramón 2008a, 2013).

${ }^{2}$ Me limito aquí a los rasgos espaciales del modelo alfarero, ya que son los que permiten la traducción entre evidencias arqueológicas y documentales. El modelo no debe ir aislado del tipo de organización social o política que representa, pero aquí enfatizo en la etapa previa: la identificación espacial de los pasos de la cadena operativa. Un valioso ejemplo del uso de modelos alfareros que considera zonas de producción y distribución, casi único en los Andes, es Tschauner (2006) sobre Pampa de los Burros (Lambayeque), quien identifica dos tipos de alfareros para esa zona durante el Intermedio Tardío.

${ }^{3}$ Se puede consultar dos síntesis históricas recientes para el período colonial temprano atentas al universo material, en Estenssoro (2003) y Ramos (2010).

${ }^{4}$ Con estilo técnico aludo a las huellas de manufactura en el producto final, y que, etnográficamente, han permitido detectar el lugar donde fue producido un objeto cerámico. También se le conoce como estilo interno o de manufactura, en contraposición al estilo externo o decorativo. Con base en la evidencia etnográfica se ha sugerido que los cambios en el estilo decorativo se vincularían a transformaciones políticas ( $v . g$. la conquista inca), mientras que el estilo de manufactura es más arraigado, más difícil de modificar. Observaciones en esta dirección podrían remontarse a los estudios etnográficos de Foster (1948) en México y Reichel-Dolmatoff (1945) en Colombia. Sobre esta discusión ver Dietler y Herbich (1989) y, especialmente, Gosselain (2002). Para el período precolonial, la distinción estilística indicada debe ser explorada antes de establecer generalizaciones.

5 Para los Andes, estoy pensando aquí en valiosos trabajos sobre producción alfarera como el de Bernier (2005: 64-70, 239-241, 263), sobre Moche. Comienzan enfatizando la necesidad de emplear modelos arqueológicos «puros» pero terminan incorporando etnografía.

${ }^{6}$ Tal es el caso de aquella realizada en el primer capítulo de Peacock (1982) sobre el imperio romano.

${ }^{7}$ En adelante, para localizar los principales sitios mencionados en el texto, ver Fig. 2. 
${ }^{8}$ Sabemos más de los alfareros coloniales tempranos gracias a los arqueólogos interesados en el período inca, que por los historiadores. En términos documentales, la información sobre alfareros urbanos es más frecuente que sobre sus pares del campo. Sobre artesanos rurales, emprendí dos tipos de búsquedas. Primero, realicé búsquedas intensivas en relación con lugares asociados a olleros coloniales y republicanos, principalmente en el Archivo General de la Nación, el Archivo Histórico de la Municipalidad de Lima, Archivo Arzobispal de Lima, Archivo Regional de Piura, Archivo Regional de La Libertad, Biblioteca Nacional, entre otros. Segundo, efectué una búsqueda extensiva en crónicas, documentos sobre extirpación de idolatrías y visitas. Los mejores documentos son los litigios vinculados con artesanos oficialmente desplazados por los incas como los casos de Shultín (Cajamarca) y Milliraya (Puno). Mucha de esta información procede de los múltiples artículos de Espinoza, quien raramente identifica sus fuentes con precisión. Por ello, el mejor análisis de los dos casos citados es de Spurling (1992). En comparación con estos litigios, las visitas son principalmente listados, salvo excepciones. Sobre alfareros urbanos, me he centrado en Lima, con las fuentes que se indicarán en la sección específica.

${ }_{9}^{9}$ Archivo Nacional de Bolivia, EC 1611 No. 2: f. 34, 34v, en Spurling (1992: 197).

${ }^{10}$ Archivo Nacional de Bolivia, EC 1611 No. 2: f. 34, 34v, en Spurling (1992: 197).

${ }^{11}$ Archivo General de Indias, Esc. de Cam. 501A: f. 96v en Spurling (1992: 245-257).

${ }^{12}$ Archivo General de Indias, Patronato 95B Ramo 3, f. 121r, en Rostworowski (1978: 228).

${ }^{13}$ Mori y Malpartida [1549] 149r-v, 153r, 156v; 290, 293, 296). La información sobre Payna es algo confusa (ver Ramón 2008a: 114).

${ }^{14}$ Collaguas III [1604-1617]: 607-617. Comala es el poblado de la novela Pedro Páramo.

${ }^{15}$ Ambas categorías pueden compararse al attached e independent potter (Costin 2001). Por varias razones prefiero mantener la división que sugiero. Una de ellas es que el ollero local puede trabajar en su comunidad o también ser desplazado a lugares intermedios para trabajar.

${ }^{16}$ Archivo General de Indias, Justicia 458, f. 2053v, Netherly 1977: 244-245, Rostworowski 1977: 232, énfasis agregado.

${ }^{17}$ El término sañucamayoc es usado por diversos autores coloniales (Acosta 1962[1590]:301, Murúa 2004[1590?]: 209-210). Mancallutac, solo por Guaman Poma (1980[1615]: 193), y coincide con el término largamente documentado en estudios etnográficos.

18 Janusek (1999: 110, 126) sugiere que su modelo se basa en documentación etnohistórica ( a wealth of ethnohistorical documents»); sin embargo, solo cita una fuente del período colonial temprano, que solo tiene una brevísima referencia a alfareros (Mercado de Peńalosa 1965 [1583]: 337). Otras críticas a su propuesta sobre alfareros en Ramón y Bell (2013: 606, n. 14).

${ }^{19}$ Esta observación se basa en mi experiencia personal de revisión de colecciones coloniales y en excavaciones, como el proyecto arqueológico Cinco Cerros (Huarochirí) a cargo de Ramiro Matos y José Pino (2003).

${ }^{20}$ Hay un segundo texto complementario de Toledo (1924[1570-5]: 171) contra los potenciales productores de objetos: «...proveeréis, en entrando en cada repartimiento, que ningún oficial de aquí en adelante, labre ni pinte las tales figuras, so graves penas, las cuales executaréis en sus personas y bienes lo contrario haciendo».

${ }^{21}$ Archivo General de Indias, en Espinoza (1987, I: 201), sin indicar localización precisa. Probablemente en Justicia 461, f. 1467 según Rostworowski (1977: 232), quien solo observa que iban a «vender sus piezas de cerámica», no moverse para producir. Este es un buen ejemplo de como los «lugares comunes» académicos pueden condicionar la interpretación de los documentos. 
${ }^{22}$ Archivo Arzobispal de Lima, Papeles importantes, Leg. 3, Exp. 13. Contiene documentos desde 1594 a 1616. Hay una coincidencia no explicada entre el nombre del pueblo y los famosos médicos itinerantes bolivianos, los Callaguaya.

${ }^{23}$ Archivo Arzobispal de Lima, Papeles importantes, Leg. 3, Exp. 13, 14 r.

${ }^{24}$ En el Leg. 3. Exp. 5 Hechicerías, Archivo Arzobispal de Lima, se alude a «pueblo de Sn Fco Calaguaya de los Olleros» (1660).

${ }^{25}$ En el Libro de Cabildos de Lima (en adelante LCL) hay toda una serie de alusiones a alfareros urbanos durante el siglo dieciséis y temprano diecisiete, al menos desde 1571. Los originales del LCL están depositados en el Archivo Histórico de la Municipalidad de Lima, en esta ocasión se usan los volúmenes transcritos y publicados por B. Lee y J. Bromley. La alusión más temprana al sitio de Olleros en las alturas meridionales de Lima, es de 1536 ( «[...] otro paso que se dice de los Olleros»; Porras 1959: 272).

${ }^{26}$ La polémica por el control de precios de la alfarería perdurará. En enero de 1577 hubo un litigio entre los alfareros, representados por tres "oficiales de labrar barro», y por las autoridades limeñas (Harth-Terré y Márquez 1958: 424-426, énfasis agregado).

${ }^{27}$ El Diccionario de Autoridades (1732) define loza como «Todo lo que se fabrica de barro fino y lustroso, como son platos, fuentes y escudillas». Técnicamente podemos tener vasijas lustrosas sin vidriar.

${ }^{28}$ Esta serie de distinciones entre los diversos tipos de productos es clave para discutir sobre producción alfarera en Lima. La expresión "por vidriar» también es usada por Cobo (1890[1653]: I:241) y alude a la vajilla sin vidriar. Además de loza, los olleros urbanos producían, a veces en el mismo taller, azulejos y cañerías (Ramírez 1999: 183). Lamentablemente Harth-Terré y Márquez 1958 no precisan su fuente.

${ }^{29}$ A todo esto puede agregarse que también en la primera mitad del siglo diecisiete, en Trujillo, el ollero Salvador Sánchez tenía el revelador título de "official de losa de talavera» (Archivo Departamental de la Libertad, Cabildo, Causas Ordinarias 17/334, 1r; 1615).

${ }^{30}$ El arqueólogo Miguel Fhon (comunicación personal) me mostró vasijas coloniales con las evidencias de defectos en el proceso productivo en el sitio Bodega y Quadra. Este material todavía está siendo procesado, y será publicado por él próximamente. Todavía necesitamos precisiones cronológicas y cuantitativas.

${ }^{31}$ Mogrovejo (1996: 33-34) indica la presencia de trípodes y pines empleados para separar vasijas en el horno (ver Fairbanks 1972: fig. 7). Según Fhon (comunicación personal), en Bodega y Quadra también se encontraban estas herramientas, e incluso se llegó a mencionar platos de alfarero, pero no los pude observar. A mi juicio, lo importante de esta evidencia es que soporta materialmente la temprana propuesta de Mogrovejo sobre producción local, básicamente soslayada por la literatura anglosajona sobre cerámica colonial sudamericana.

${ }^{32}$ La vasija tipo Olleros aquí tratada adquiere más valor si consideramos que luego de las excavaciones suele formar parte de las «no diagnósticas», y en los museos, de las «no exhibibles», es decir aquellas raramente publicadas y relegadas a los depósitos. Paradójicamente, es el tipo de vasija cuantitativamente más importante, y la vía de acceso para escribir una arqueología coherente de las clases subalternas.

${ }^{33}$ Debe haber una densidad informativa semejante para el caso de la cerámica colonial temprana del norte peruano, y para el área alrededor del Cuzco, donde también se conocen centros alfareros precoloniales que siguieron produciendo en épocas coloniales. 


\section{FUENTES MANUSCRITAS}

Archivo Arzobispal de Lima

1594- Papeles Importantes Leg. 3, Exp. 13.

1611

1660 Hechicerías Leg. 3. Exp. 5.

Archivo Departamental de La Libertad (Trujillo)

1615 Expediente seguido por Salvador Sánchez contra el Licenciado Francisco Gutiérrez Sala Blanca sobre ciertas cantidades que es deudor a diferentes personas y demás deducidos. Cabildo, Causas Ordinarias $17 / 334$.

Archivo General de Indias (Sevilla)

1600- Don Miguel Ramos contra Sebastián Ninalingón. Escribanía de Cámara 501 A.

1608

1573 Residencia tomada al doctor Gregorio González de Cuenca, oidor de la Real Audiencia de los Reyes y a sus oficiales, de la visita hecha a la provincia de Trujillo, por el licenciado Pedro Sánchez de Paredes, oidor de dicha Audiencia (Tercer Legajo). Justicia 458.

1572- Residencia tomada al doctor Gregorio González de Cuenca, oidor de la Audiencia de Lima, y a sus

1573 oficiales, del tiempo que fue visitador de la provincia de Trujillo, por el licenciado Pedro Sánchez de Paredes, también oidor en la misma audiencia (Sexto legajo). Justicia 461.

1557 Méritos y Servicios de Nicolás de Ribera, Perú. Patronato 95B Ramo 3, 110r-150r.

Archivo Histórico de la Municipalidad de Lima

s.f. Libro de Cabildos de Lima.

Archivo Nacional de Bolivia (Sucre)

1611 EC No 2.

\section{REFERENCIAS}

Acevedo, $S$.

1986 Trayectoria de la cerámica vidriada en el Perú, en: F. Stastny y S. Acevedo (eds.), Vidriados y mayólica del Perú, 19-31, Universidad Nacional Mayor de San Marcos, Lima.

Acevedo, S. (ed.)

2004 La loza de la tierra. Cerámica vidriada en el Perú, Universidad Ricardo Palma/Instituto Cultural Peruano Norteamericano, Lima.

Acosta, J.

1962 Historia natural y moral de las Indias, Fondo de Cultura Económica, Ciudad de México. [1590]

Bell, M.

2007 Negotiating the pottery exchange landscape, tesis de maestría, Universidad de Wisconsin.

Bernier, $\mathrm{H}$.

2005 Étude archéologique de la production artisanale au site Huacas de Moche, côte nord du Pérou, tesis de doctorado, Universidad de Montreal, Montreal.

Bushnell, G.

1959 Some post-columbian whistling jars from Peru, en: Actas del XXXIII Congreso Internacional de Americanistas, II: 416-20, San José.

Cobo, B.

1890 Historia del Nuevo Mundo, Sociedad de Bibliófilos Andaluces, Sevilla.

[1653]

Contreras, $\mathrm{M}$.

1968 Padrón de indios de Lima, Seminario de Historia Rural Andina, Lima.

[1613]

Costin, C.

2001 Production and exchange of ceramics, en: D'Altroy y C. Hastorf (eds.), Empire and domestic economy, 203-42, Kuwler, New York. https://doi.org/10.1007/0-306-47192-2_9 


\section{Cummins, T.}

1997 Images and objects: the object of imaginary in colonial native Peru as seen through Guaman Poma Nueva Coronica y Buen Gobierno, Journal of the Steward Anthropological Society 25: 237-273.

Desrosiers, $S$.

1986 An interpretation of technical weaving data found in an early 17th-century chronicle, en: A. Rowe (ed.), The Junius B. Bird conference on Andean textiles, 219-241, The Textile Museum, Washington D. C.

Dietler, M. y I. Herbich

1989 Ceramics and ethnic identity: Ethnoarchaeological observations on the distribution of pottery styles and the relationship between the social contexts of production and consumption, en: F. Audouze y D. Binder (eds.), Terre cuite et société: La céramique, document technique, économique, culturel, 459-472, Editions APDCA, Antibes.

Espinoza, W.

1987 Artesanos, transacciones, monedas y formas de pago en el mundo andino. Siglos XV y XVI, Banco Central de Reserva del Perú, Lima.

Estenssoro, J. C.

2003 Del paganismo a la santidad. La incorporación de los indios del Perú al catolicismo 1532-1750, Pontificia Universidad Católica del Perú/ Instituto de Estudios Peruanos, Lima.

Fairbanks, C.

1972 The cultural significance of Spanish Ceramics, en: I. Quimby (ed.), Ceramics in America, 141-174. University of Virginia Press, Charlottesville.

Feltham, J.

2009 La arqueología de Sisicaya, en: F. Salomon, J. Feltham y S. Grosboll (eds.), La revisita de Sisicaya, 1588, 57-101, Pontificia Universidad Católica del Perú, Lima. https://doi.org/10.4000/bifea.5157

Feltham, J. y P. Eeckout

2004 Hacia una definición del estilo Ychsma: aportes preliminares sobre la cerámica Ychsma Tardía de la Pirámide III de Pachacamac, Bulletin de l'Institut Francais d'Etudes Andines 33, 643-67.

Foster, G.

1948 Some implications of modern Mexican mold-made pottery, Southwestern Journal of Anthopology 4, 356-370.

\section{Goggin, J.}

1968 Spanish majolica in the New World. Types of the sixteenth to eighteenth centuries, Yale University, New Haven.

\section{Gosselain, O.}

2002 Poteries du cameroun meridional, CNRS Editions, Paris.

Guaman Poma, F.

1980 Nueva coronica y buen gobierno, Siglo Veintiuno, México.

[1615]

Harth-Terré, E.

1986 Pedro Ramírez, en: Diccionario Histórico y Biográfico del Perú: siglos XV-XX, t. VII, 352-353, Milla Batres, Lima.

Harth-Terré, E. y A. Márquez

1958 Las bellas artes en el virreinato del Perú en el siglo XVII, azulejos limeños, Revista del Archivo Nacional del Perú 22, 411-454.

1963 Las bellas artes en el virreinato del Perú. Perspectiva social y económica del artesano virreinal en Lima, Revista del Archivo Nacional del Perú 26, 353-446.

Hayashida, F.

1995 State pottery production in the Inka provinces, tesis de doctorado, Universidad de Michigan, Ann Arbor.

\section{Hernández Príncipe, R.}

2003 Visita.... Recuay, en: P. Duviols (ed.), Procesos y visitas de idolatrias: Cajatambo, siglo XVII con documentos y

[1622] anexos, Instituto Francés de Estudios Andinos/ Pontificia Universidad Católica del Perú, Lima. 
Janusek, J.

1999 Craft and local power: embedded Specialization in Tiwanaku cities, Latin American Antiquity 10 (2), 107-131. https://doi.org/10.2307/972198

Julien, C.

1993 Finding a fit: archaeology and ethnohistory of the Incas, en: M. Malpass (ed.), Archaeological and ethnohistorical assessment of the impact of the Inca State, 177-233, University of Iowa Press, Iowa.

Loayza, B.

2006 Informacion solicitada por Grabiel de Miranda ante el visitador Bernardino de Loayza para levantar los

[1573] cargos hechos en contra suya, en: W. Espinoza (ed.), La etnia Guayacundo en Ayabaca, Huancabamba y Caxas (siglos XV-XVI), 272-294, Pedagógico de San Marcos, Lima.

Matayoshi, N.

1988 Mankalluta. Relatos orales de ceramistas, Kamaq Maki 2, 12-13.

Mayer, E.

1983 Fruhkoloniale "Chimu" keramik von der peruanischen nordkuste, Beitrage zur Allgemeinen un Vergleichenden Archaeologie 5, 431-442.

Menzel, D.

1960 Archaism and revival on the South Coast of Peru, en: F. Wallace (ed.), Men and cultures, 595-600, University of Pennsylvania Press, Philadelphia.

1977 The archaeology of ancient Peru and the work of Max Uhle, Lowie Museum of Anthropology, Berkeley.

Mercado de Peñalosa, P.

1965 Relación de la provincia de los Pacajes, en: Relaciones geográficas de Indias, vol. 83, 334-341, Biblioteca de

[1583] de Autores Españoles, Madrid.

Miasta, J.

2006 Arqueología histórica de Huarochirí, Seminario de Historia Rural Andina/Universidad Nacional Mayor de San Marcos, Lima.

Mogrovejo, J.

1996 Arqueología urbana de evidencias coloniales en la ciudad de Lima, Instituto Riva Agüero, Lima.

Mori, J. y H. Malpartida

1967 La visitación de los pueblos de Indios, en: Visita de la provincia de León de Huánuco en 1562, 289-310,

[1549] Universidad Nacional Hermilio Valdizán, Huánuco.

Murra, J.

2002 Las etnocategorías de un khipu estatal, en: El mundo andino, población, medio ambiente y economía, 248-260, Pontificia Universidad Católica del Perú/ Instituto de Estudios Peruanos, Lima.

Murúa, $M$.

2004 Historia del origen y genealogía real de los reyes incas del Piru de sus hechos, costumbres, trajes, y manera de [1590?] gobierno, Testimonio, Madrid.

Netherly, P.

1977 Local level lords on the north coast of Peru, tesis de doctorado, Cornell University, Ithaca.

Noack, K.

1996 Gregorio González de Cuenca: Visitador y legislador en la costa norte, Perú, siglo XVI (1566/67), Indiana 14, 141-156.

O'Phelan, S.

2001 Una rebelión abortada. Lima 1750: La conspiración de los indios olleros de Huarochirí, Varia História 24, 7-32.

Paniagua, J. y D. Truhan

2003 Oficios y actividad paragremial en la Real Audiencia de Quito (1557-1730): El corregimiento de Cuenca, Universidad de León, León.

Peacock, D.

1982 Pottery in the Roman world: an ethnoarchaeological approach, Longman, Londres/New York. 
Porras, R. (ed.)

1959 Cartas del Perú (1524-1543), Sociedad Peruana de Bibliófilos, Lima.

Prieto, G.

2008 Cerámica utilitaria chimú de San José de Moro: tipología de formas y modelos interpretativos, Revista del Museo de Arqueología, Antropología e Historia 10, 111-154.

Ramírez, L.

1999 Azulejos y evangelización en Lima colonial, Historia y Cultura 23, 177-215.

Ramírez, S.

2007 It's all in a day's work: occupational specialization on the Peruvian north coast, revisited, en: I. Shimada (ed.), Craft production in complex societies, 262-280, University of Utah Press, Salt Lake City.

Ramón, G.

1999 Producción alfarera en Santo Domingo de los Olleros, Bulletin de l'Institut Francais d'Etudes Andines 28(2), 215-248. https://doi.org/10.4000/bifea.2985

2008a Potters of the northern peruvian Andes. A palimpsest of technical styles in motion, tesis de doctorado, University of East Anglia, Norwich.

2008b Producción alfarera en Piura: diacronía y estilos técnicos, Bulletin de l'Institut Francais d'Etudes Andines 37 (3), 477-509. https://doi.org/10.4000/bifea.2985

2011 The swallow potters. Itinerant styles in the Andes, en: S. Scarcella (ed.), New perspectives on creamic studies, 160-175, British Archaeological Reports, Oxford.

2013 Los alfareros golondrinos. Producción itinerante en los Andes Centrales, Instituto Francés de Estudios Andinos/ Sequilao, Lima.

Ramón, G. y M. Bell

2013 Re-placing plainware: production and distribution of domestic pottery, and the narration of the precolonial past in the Peruvian Andes, Journal of Anthropological Archaeology 32 (4), 595-613. https://doi. org/10.1016/j.jaa.2013.09.005

Reichel-Dolmatoff, G.

1945 La manufactura de cerámica entre los Chami, Boletin de Arqueología 1, 425-30.

Renfrew, C.

1974 Trade as Action at a Distance: Questions of Integration and Communication, en: J. Sabloff y C. LambergKarlovsky (eds.), Ancient civilization and trade, 3-59, University of New Mexico Press, Alburquerque.

Rice, P.

1996 Peru's colonial wine industry and its European background, Antiquity 70, 785-800. https://doi.org/ $10.1017 / \mathrm{s} 0003598 \times 00084064$

Robinson, D. (ed.)

2006 Collaguas III. Yanque Collaguas: sociedad, economía y población, Pontificia Universidad Católica del Perú, [1604-17] Lima.

Rostworowski, M.

1977 Etnia y sociedad, Instituto de Estudios Peruanos, Lima.

1978 Señoríos indígenas de Lima y Canta, Instituto de Estudios Peruanos, Lima.

Rowe, J.

1944 Introduction to the archaeology of Cuzco, Harvard University Press, Cambridge.

1962 Stages and periods in archaeological interpretation, Southwestern Journal of Anthopology 18, 40-54. https://doi.org/10.1086/soutjanth.18.1.3629122

Sabogal, J.

1987 Cerámica yunga: estribación andino piurana, CIPCA, Piura.

Salinas y Córdova, B.

1957 Memorial de las historias del Nuevo Mundo, Universidad Nacional Mayor de San Marcos, Lima.

[1653]

Salomon, F.

1985 The dynamic potential of the complementarity concept, en: S. Masuda, I. Shimada y C. Morris (eds.), Andean ecology and civilization: an interdisciplinary perspective on Andean ecological complementarity, 511-31, University of Tokyo Press Tokio. 
Sillar, B.

2000 Shaping culture. Making pots and constructing households. An ethnoarchaeological study of pottery production, trade and use in the Andes, British Archaeological Reports, Oxford.

Spurling, E.

1992 The organization of craft production in the Inka state: the potters and weavers of Milliraya, tesis de doctorado, Universidad de Cornell, Ithaca.

Toledo, F. de

1924 Libro de visita general del virrey Toledo (1570-1575), Revista Histórica 7, 117-216.

[1570-75]

1986 Francisco de Toledo. Disposiciones gubernativas para el virreinato del Perú, Escuela de Estudios Hispano[1569-75] Americanos/Consejo Superior de Investigaciones Científicas, Sevilla.

Tschauner, $\mathrm{H}$.

2006 Chimu craft specialization and political economy: A view from the provinces, en: W. Isbell y $\mathrm{H}$. Silverman (eds.), Andean Archaeology III: North and South, vol. 3, 171-196, Springer, New York. https://doi.org/10.1007/0-387-28940-2_8

Vázquez de Espinoza, A.

1968 Compendio y descripción de las Indias Occidentales, Smithsonian Institution Press, Washington, D.C.

[1620]

Wernke, $S$.

2013 Negotiated settlements. Andean communities and landscapes under Inka and Spanish colonialism, University Press of Florida, Gainsville. https://doi.org/10.5744/florida/9780813042497.001.0001

Wylie, A.

2002 Thinking from things. Essays in the philosophy of archaeology, California University Press, Berkeley. https://doi.org/10.2307/25606173 